\title{
O PROCESSO DE TRANSIÇÃO DE EMPREENDIMENTOS RURAIS TRADICIONAIS PARA AS AGROINDÚSTRIAS ASSOCIATIVAS NO ESTADO DE PERNAMBUCO: DESAFIOS PARA CONSTRUIR COMPETÊNCIAS EMPREENDEDORAS THE TRANSITION PROCESS FROM TRADITIONAL RURAL UNDERTAKINGS TO ASSOCIATIVE AGRO INDUSTRIES IN THE STATE OF PERNAMBUCO: CHALLENGES FOR BUILDING ENTREPRENEURIAL SKILLS
}

Claudio Jorge Gomes da Rocha Junior

Professor da Universidade Federal Rural de Pernambuco (UFRPE), Serra Talhada (PE), Brasil

\section{Romilson Marques Cabral}

Professor do Departamento de Administração Universidade Federal Rural de Pernambuco

(UFRPE), Serra Talhada (PE), Brasil
Data de recebimento: 16-01-2015

Data de aceite: 23-10-2015

\section{RESUMO}

O presente trabalho identifica dificuldades e potencialidades dos agricultores estudados para se construir os atributos denominados "competências empreendedoras". A pesquisa é baseada no empreendedorismo rural com destaque para competências empreendedoras. Neste estudo qualitativo com análise de conteúdo, busca-se: identificar as principais dificuldades e potencialidades para que os agricultores assimilem as novas competências empreendedoras necessárias na viabilização das agroindústrias e examinar a compatibilidade das ações adotadas pelas empresas de apoio à agricultura familiar com a realidade dos agricultores que ingressaram no empreendedorismo por meio da agroindustrialização da produção. Foram entrevistados nove agricultores líderes de três agroindústrias associativas das regiões Agreste e Sertão de Pernambuco e doze técnicos de nove instituições de apoio à agricultura familiar. Nas fábricas que apresentaram resultados negativos, seus gestores apresentaram grandes deficiências de competências empreendedoras. Por fim, estão contidas sugestões para os agricultores empreendedores superarem adversidades, bem como para auxiliar técnicos de campo (extensionistas ou não) a transporem suas deficiências.

Palavras-chave: Empreendedorismo rural; agricultura familiar; extensão rural.

\section{ABSTRACT}

This paper identifies difficulties and capabilities of the farmers studied to build the attributes called "entrepreneurial skills". The research is based on rural entrepreneurship with emphasis on entrepreneurial skills. This qualitative research which content analysis aimed to: identify the main difficulties and capabilities of farmers to assimilate the new entrepreneurial skills necessary for the viability of agro industries and examine the compatibility of the actions adopted by companies to support family farming with the reality of the farmers who engaged in entrepreneurship through the agro industrialization of production. We interviewed nine farmers from three leading associative agro industries from rural and backcountry regions of the state of Pernambuco, Brazil, and twelve technicians from nine institutions that support family farming. In the factories that presented negative results, their managers had major shortcomings of entrepreneurial skills. Lastly, the paper contributes with suggestions for farmer entrepreneurs to overcome adversity, as well as to assist field technicians (extensionists or not) to transpose their shortcomings.

Keywords: Rural entrepreneurism; family farming; rural extension. 


\section{INTRODUÇÃO}

As chances de transição da agricultura familiar tradicional (que apenas produz e comercializa alimentos) para o agricultor empreendedor (que produz, beneficia, industrializa, comercializa e combina atividades tradicionais com outras fontes de renda) são ampliadas por meio de modelos de negócios que combinam renda proveniente da atividade agropecuária e de outras fontes de riqueza (agroindústrias de pequeno porte, cultivo e/ou criação de produtos nobres, orgânicos, naturais, artesanais, confecções, de transporte, de comunicação, de turismo rural e de aventura), modelos esses que Campanhola e Silva (2004) classificam como "novo rural brasileiro". Uma das alternativas mais promissoras é a da agroindústria associativa. Quanto a isso, este trabalho buscou analisar as ações adotadas pelos órgãos de apoio e as facilidades e dificuldades encontradas pelos agricultores familiares para sua formação empreendedora.

Tanto Batalha (2007) quanto Neves e Conejero (2007) destacam as grandes e médias agroindústrias como propulsoras do desenvolvimento de regiões. Porém, diante de cenários de crise, a geração de postos de trabalho e renda provenientes de pequenas agroindústrias também ganhou relevância nos bastidores políticos, financeiros e acadêmicos. Tendo isso em vista, fica a questão se cabe incentivar os agricultores familiares a ser empresários ou apenas os que possuem perfil para tal - e qual seria esse perfil? As competências empreendedoras apontam quais características um bom administrador com perfil empreendedor deve possuir (PAIVA JUNIOR, 2008). Sendo assim, quais competências empreendedoras estão sendo desenvolvidas pelos agricultores para tornar suas unidades agroindustriais mais sustentáveis?

Este trabalho foi resultado de uma proposta de estudo qualitativo em três comunidades rurais de Pernambuco e objetivou: 1) identificar as principais dificuldades e potencialidades para que os agricultores assimilem as novas competências empreendedoras necessárias na viabilização das agroindústrias; 2) verificar a compatibilidade das ações dos órgãos de apoio para a viabilização dos empreendimentos associativos.

\section{REVISÃO DE LITERATURA}

\subsection{Agricultura familiar tradicional}

A classificação brasileira para estabelecimentos rurais familiares depende simultaneamente de que o produtor rural familiar seja proprietário e de que a mão de obra utilizada, originária da própria família, obedeça a limites de renda fixados pelo Programa Nacional de Fortalecimento da Agricultura Familiar (Pronaf) conforme a Lei no 11.326/2006.

As mudanças no sistema de distribuição de alimentos, ocorrida após a introdução das grandes redes de supermercados e das grandes agroindústrias, aumentou a concorrência do setor e, devido a exigências em padronização, oferta regular e qualidade, dificultou a agricultura familiar por fornecer alimentos industrializados (WILKINSON, 2008). Uma das possibilidades mais rentáveis para a agricultura familiar é sua inserção no mercado por meio de agroindústrias, pois permite a eliminação ou redução dos atravessadores (intermediários), diminui as perdas excessivas durante a safra, possibilita um preço mais estável (devido à maior conservação dos produtos) e agrega um maior valor à produção.

\subsection{O papel das agroindústrias}

A viabilidade das agroindústrias depende de seu porte? Para Müller (1982), o sucesso dos empreendimentos agroindustriais é indiferente ao porte, contudo, quanto maior o grau de utilização de tecnologia (progresso técnico), mais comum é 
esse sucesso. Além disso, apesar de a expansão das agroindústrias ser determinante para redefinir o papel da agropecuária na economia nacional, a industrialização dos produtos rurais não melhorou as condições sociais da população do campo (GOODMAN; SORJ; WILKINSON, 1985). Porém, de alguma maneira, após longo período de análise (1985-2010), Wilkinson continua a considerar a importância do desenvolvimento tecnológico para a agroindústria. A agricultura familiar ganha peso no sistema agroindustrial e é de importância estratégica para a melhoria na alimentação das categorias menos favorecidas. Portanto, a melhor maneira de gerar empregos, aquecer a economia e consequentemente desenvolver os territórios, seria combinar a agricultura familiar e o agronegócio no desenvolvimento agroindustrial do país (WILKINSON, 2010). É inegável a relevância das agroindústrias para o desenvolvimento econômico de uma nação, e cada vez mais as pequenas agroindústrias ganham importância nesse cenário, já que são criadoras de postos de trabalho e, quando bem conduzidas, permitem uma boa distribuição de renda.

\subsubsection{Agroindústria associativa}

A agroindustrialização tem sido adotada para suprir a baixa remuneração obtida por outras explorações econômicas realizadas nas propriedades rurais - neste caso, se configura o processo de empreendedorismo por necessidade. Para tais investimentos, a dependência de máquinas, crédito e outros insumos estimulou a implementação de linhas de financiamento em prol do fomento dessa atividade (WESZ JUNIOR, 2010).

A agricultura familiar ganha crescente importância devido ao aumento da mobilização e organização dos produtores rurais e sua articulação em diversos espaços públicos. A constituição de uma agroindústria associativa acontece de forma semelhante, pois as dificuldades (por exemplo, quanto à adequação às exigências sanitárias e fiscais) só podem ser superadas mediante essas iniciativas. A discussão em torno de uma regulação mais justa aos produtos das agroindústrias associativas deve combinar a expectativa dos consumidores com o respeito às condições culturais do local de produção, para que ocorra uma maior inclusão dos pequenos produtores rurais (SULZBACHER, 2009).

A sustentabilidade das agroindústrias associativas está apoiada na consistência dos grupos, e sua manutenção depende de uma grande soma de capital social (relações sociais de cooperação e confiança) que é de difícil conquista (MIOR, 2008). O associativismo é uma poderosa ferramenta para que as agroindústrias de pequeno porte superem seus obstáculos. Além do desafio de tornar um empreendimento de médio ou pequeno porte viável, outro se apresenta: o de tornar a gestão associativa sustentável.

\subsubsection{Sustentabilidade do associativismo}

No Nordeste do Brasil, a organização de pequenos produtores em associações e cooperativas é bastante complexa. Os principais motivos que impulsionam esse agrupamento são o desemprego e a necessidade de produzir bens e serviços e de proporcionar qualidade de vida à população associada (OLIVEIRA, 2006).

Mesmo diante das dificuldades encontradas, o associativismo é uma excelente forma de organização para o desenvolvimento local (OLIVEIRA, 2006; (AMPANHOLA; SILVA, 2004), apesar de, no Brasil, ainda precisar de grandes avanços. No entanto, o associativismo educacional, que objetiva formar e capacitar as pessoas, principalmente no empreendedorismo, ganha crescente espaço. (OLIVEIRA, 2006).

A grande dificuldade dos líderes de pequenos negócios é desenvolver profissionalismo sem perder o perfil empreendedor (LONGENECKER et al., 2013). No caso das empresas rurais, outro desafio 
é manter a essência da agricultura familiar, ou seja, combinar a vida simplificada do homem do campo com o estilo de vida empresarial.

\subsection{O empreendedorismo}

O termo "empreendedor" provém da palavra francesa "entrepreneur" e significa "a pessoa que assume riscos e começa algo novo" (DORNELAS, 2008). Para Drucker (2005), entretanto, em geral os empreendedores não possuem a característica de assumir riscos. Já Dornelas (2008) diz que o empreendedor assume riscos calculados e que sabe gerenciá-los para obter sucesso em suas iniciativas. A transição da cultura do empregado para a do empreendedor é muito sofrida, mas essa dificuldade pode ser amenizada quando há no local um ambiente propício para a criação de novos negócios. Também vale salientar a figura do empreendedor que atua em ambientes não muito favoráveis, estando assim condicionado a assumir mais riscos (LEITE, 2000).

As características de inovatividade, assunção de riscos, orientação para mudanças e oportunismo têm sido eficazes para o treinamento e desenvolvimento de gerentes empreendedores (LAU et al., 2012).

Quando realizado no próprio ambiente de trabalho ou em contextos semelhantes, o processo de aprendizagem do empreendedorismo é efetivo e as atividades de transformação, ou seja, o acúmulo de experiência por meio da realização de tarefas empresariais, consolida os resultados de aprendizagem, pois possibilita maior aplicação ou transferência dos próprios resultados e de outrem na hora de realizar as tarefas empreendedoras (MAN, 2012).

No cenário empresarial, há quem não se contente apenas em seguir outros e busque, no empreendedorismo, tornar-se reconhecido por gerar empregos, inovar e promover o crescimento econômico. Longenecker et al. (2013) citam a maior possibilidade de lucro, independência e prazer em viver como as principais vantagens de se ter o próprio negócio, e destacam a chance de fracasso, a maior dedicação e o desgaste emocional como desvantagens. Contudo, convém salientar, em específico quanto ao empreendedorismo rural, a dificuldade de adaptação dos agricultores familiares a essa nova maneira de trabalho, que Ihes impõe maior proximidade com o consumidor final, necessidade de mais racionalidade na utilização dos recursos e, por fim, maior contato com ferramentas de gestão. Entretanto, em vez de falar em "empreendedorismo", poderia ser considerado dizer "empreendedorismos", pois, dadas as circunstâncias, diferentes segmentos podem encaminhar a diversas formas de empreender, sendo uma delas o empreendedorismo rural.

\subsubsection{O empreendedorismo no meio rural}

Como fatores inibidores do empreendedorismo rural, destacam-se a imagem social - ou seja, como a sociedade, rural e urbana, enxerga o agricultor -, a disposição para assumir riscos - os quais, em geral, os produtores rurais evitam - e o capital social - características de relacionamento entre os habitantes de uma região, como o nível de cooperação, confiança e organização local (LOPES; NANTES, 2008).

Será que, para o sucesso do empreendedorismo no meio rural, é necessário transformar os produtores em empresários? Lopes e Nantes (2008) acreditam que sim, e ainda salientam que isso implica em mais trabalho para o agricultor - por isso, a mudança deve ser feita com cautela e planejamento, e o êxito aumenta o reconhecimento do empresário rural na comunidade, devido à relevância dos resultados positivos de sua iniciativa.

Diante dessa realidade, a formação de empreendedores rurais competentes adquire relevância. É difícil superar as barreiras na administração de um novo negócio, principalmente para os agricultores familiares que, ao ingressar no mercado por 
meio das agroindústrias associativas, encontrarão diversos obstáculos a transpor, como competitividade e sustentabilidade para o meio-ambiente e a economia, adequação de seus produtos e empresa às exigências sanitárias e dos consumidores e conhecimento de ferramentas de gestão, marketing e desenvolvimento de produtos - características essas que McClelland (1973) e Zarifian (2001) definem como competências.. Batalha (1995) destaca a importância da formação de gerentes para enfrentarem esses e outros desafios.

\subsection{Competências}

A intensa competição exige que as empresas realizem buscas contínuas por inovação. Delimitar características individuais para um trabalhador ter bom rendimento seria insuficiente, pois o trabalho deixa de ser apenas as tarefas que se relacionam a cargos ou posições, passando a figurar como uma mistura de operações e da capacidade do indivíduo em resolver situações imprevistas, que se tornam mais comuns (FLEURY; FLEURY, 2004). Uma boa formação de competências individuais necessita não só de um conjunto de saberes e aptidões, mas da capacidade de ação em utilizar essas características para contribuir com sua empresa e aprimorar seu próprio valor (Ibidem, 2004).

Zarifian (2001) exprime que a competência é a qualidade do indivíduo, e não de seu cargo ou atividade de trabalho, e que ela se manifesta em ações práticas, ou seja, no cotidiano da vida profissional. Para o autor, essa visão se torna vaga quando esse profissional é avaliado de maneira isolada, já que não poderia ser examinado dentro de um contexto social (relações e interações de trabalho) e econômico (desempenho).

Por fim, competência é o conjunto de conhecimentos, habilidades e atitudes de um indivíduo diante dos desafios profissionais, que, segundo Zarifian (2001), depende da iniciativa e responsabilidade do empreendedor.
Ruppenthal e Cimadon (2012) traçam um modelo de ações desejáveis para o desenvolvimento das competências gerenciais, que segundo os autores são determinantes para o sucesso dos empreendedores. Entre as práticas, destacam os relacionamentos (sistema de relações) e a observação de casos de sucesso como alguns dos ativadores da inteligência empreendedora. Para eles, o aumento da assertividade nos empreendimentos surgidos por necessidade depende ainda da capacidade de visão, motivação e liderança dos donos de negócios.

\subsubsection{Competências empreendedoras}

A competência de um empreendedor depende da interação entre seus conhecimentos (em relação às exigências do consumidor, da organização e dos produtos e serviços), habilidades (melhor atendimento e satisfação das necessidades do público-alvo) e atitudes (estratégias para atender os clientes) para maximizar a utilização dos recursos (tempo, mão de obra, dinheiro, ferramentas) e conseguir atender a demanda por seus produtos (PAIVA JUNIOR, 2008).

Segundo Man e Lau (2005), nos ambientes industriais de Hong Kong, China, apesar das intensas transformações econômicas, as características empreendedoras responsáveis pelo desempenho superior no trabalho se mantiveram e, entre elas, os autores destacam: orientação por resultados, dedicação ao trabalho, facilidade de relacionamento e senso de independência, esse último estimulado pelos pais.

Paiva Junior (2008) considera sete tipos de competências relevantes para qualificar um empreendedor. São elas: I) competência de oportunidade: capacidade de identificar, avaliar ou buscar oportunidades; II) competência de relacionamento: capacidade de enquadrar a empresa e a si mesmo em redes de relacionamentos, para o bom desenvolvimento pessoal e da organização; III) 
competência conceitual: habilidade de resolver de forma inovadora os problemas encontrados na organização e de tomar decisões ágeis; IV) competência administrativa: habilidade de aperfeiçoar o uso dos recursos disponíveis na empresa a fim de melhorar de forma contínua o desempenho da organização, utilizando os princípios da administração (planejamento, organização, direção e controle) para isso; V) competência estratégica: capacidade de planejar e implementar estratégias para sustentar a competitividade da empresa a longo prazo e na inserção da organização no mercado a curto e médio prazo; VI) competência de comprometimento: capacidade de se entregar ao trabalho, principalmente em situações de difícil controle, sendo essa uma das características mais influentes para o empreendedor rural, estimulada pelos valores pessoais do empreendedor; VII) competência de equilíbrio do trabalho e da vida pessoal: elemento importante para a manutenção do bem-estar no ambiente de trabalho, refletindo diretamente no desempenho pessoal na organização.

\section{METODOLOGIA}

Esta pesquisa tem natureza qualitativa, sendo classificada como estudo de caso múltiplo e explicativo. A unidade de análise consiste nas lideranças das agroindústrias associativas. Os autores Gibbs (2009), Strauss; Corbin (2009), Bardin (2008) e Franco (2008) foram à base para a formulação do modelo de análise do conteúdo da pesquisa. A área de execução se deu em três agroindústrias pernambucanas inseridas no Agreste - Agroindústria de pequeno porte do Povoado Pedra do Rodeadouro, em Bonito, que produz polpa e doces de frutas - e Sertão - Agroindústria de pequeno porte Mãos Crioulas, em Afogados da Ingazeira, produtora de castanha-de-caju, e Associação de Desenvolvimento Rural e Sustentável da Serra (Adessu) da Baixa Verde, em Triunfo, que produz derivados da cana-de-açúcar.

\subsection{Amostra e seus critérios}

A amostra é composta de nove lideranças, sendo três de cada agroindústria. Os entrevistados foram selecionados pelos associados por apresentar capacidade de liderança e por possuir conhecimento das pessoas e da história das comunidades pesquisadas. Dado o tamanho das agroindústrias e a pequena quantidade de associados, o número de três entrevistados foi representativo para cada unidade. A amostra é não probabilística e representa a intencionalidade da pesquisa e a acessibilidade para coleta de dados.

Além das lideranças das agroindústrias, foram entrevistados doze técnicos de campo de nove organizações: Agência de Defesa e Fiscalização Agropecuária de Pernambuco, (Adagro), Banco do Nordeste do Brasil (BNB - Central Operacional Recife), Centro Agroecológico Sabiá, Cooperativa dos Profissionais em Atividades Gerais (Coopagel), Instituo Agronômico de Pernambuco (IPA - Afogados da Ingazeira, Recife e Serra Talhada, PE), Ministério da Agricultura, Pecuária e Abastecimento (MAPA), Serviço de Inspeção Vegetal (SIV), Ministério do Desenvolvimento Agrário (MDA), Instituto Nacional de Colonização e Reforma Agrária (Incra - Recife), Secretaria de Agricultura e Reforma Agrária de Pernambuco (SARA), Programa de Apoio ao Pequeno Produtor Rural de Pernambuco (ProRural) e Universidade Federal Rural de Pernambuco (UFRPE). Os técnicos entrevistados foram apontados pelos dirigentes dessas entidades por apresentarem maior proximidade com os objetivos do estudo.

\subsection{Coleta de dados}

A partir de triangulação de dados em entrevistas e de observação e documentação, conforme o resumo:

- entrevistas: semiestruturadas (com foco nos objetivos específicos do trabalho) com os 
agricultores líderes e técnicos de apoio, preservando a identidade dos entrevistados.

- documentação: análise do conteúdo do projeto de implantação da Agroindústria de Pequeno Porte de Pedra do Rodeadouro em função das categorias analíticas correspondentes.

- observação: planejada, individual e não participante. Buscou a averiguação da ocorrência das funções básicas da administração (planejamento, organização, direção e controle) nas agroindústrias associativas.

\subsection{Modelo de análise dos resultados}

Os resultados foram obtidos por meio de análise qualitativa, e os dados colhidos de forma imparcial foram confrontados com as teorias que explicam os fenômenos abordados.

Após a etapa de coleta de dados (entrevistas, documentação e observação), foi realizada a codificação do material obtido.

A análise de conteúdo foi iniciada por meio da pré-análise (realização de leitura flutuante inicial e, posteriormente, de leitura do material obtido para permitir ordenamento e classificação das informações). Em seguida, foram atribuídas respostas às questões centrais e de campo, que possibilitou a identificação de palavras-chave relacionadas às variáveis analíticas.

O passo seguinte foi a comparação do material codificado com as teorias inerentes à pesquisa, a fim de explicar os fenômenos descritos no decorrer do estudo. Por fim, esse material foi decodificado, o que consistiu em interpretar e escrever os resultados, com o intuito de atingir os objetivos específicos da pesquisa.

\section{RESULTADOS E DISCUSSÃO}

\subsection{Deficiências e potencialidades dos agricultores familiares para o êxito das agroindústrias}

\subsubsection{Competência de oportunidade}

Os agricultores de uma fábrica de polpa de frutas entrevistados em Bonito apresentam baixo poder de articulação, carência de orientação e pouco acesso a informações. Assim, a busca por oportunidades se faz necessária para o sucesso de um empreendimento (PAIVA JUNIOR, 2008).

A fábrica de Triunfo, de rapadura, está localizada em melhores condições de infraestrutura se comparada à fábrica de polpa de fruta, e seus agricultores-líderes possuem boa articulação externa.

Já os agricultores de uma fábrica de castanhade-caju entrevistados em Afogados da Ingazeira são bastante articulados, mesmo estando a $18 \mathrm{~km}$ do centro da cidade. Nesse caso, a dificuldade de busca por novas oportunidades em vendas ainda se dá pela baixa capacidade produtiva da agroindústria.

\subsubsection{Competência de relacionamento}

Na agroindústria de Bonito, foram observadas alta centralização de informações entre os líderes e pouca sintonia deles com os outros membros. Os agricultores entrevistados possuem dificuldades em enquadrar a empresa em eficientes redes de relacionamento externo e cooperação, mesmo que a fábrica esteja inserida em uma rede de agroindústrias (Cooperasul), mas que não funciona conforme proposta inicial. Já na fábrica de Triunfo, constatou-se que o poder e as informações são mais descentralizadas e que os membros possuem boa sintonia entre si. Em Afogados da Ingazeira, os trabalhadores da fábrica de castanha-de-caju exercem tarefas pré-estabelecidas, o que revela certo grau de organização. Essas agroindústrias ainda estão em desacordo com o que propuseram Buinain (2007) e Batalha (2007), que consideram que, para os agricultores familiares obterem resultados positivos, devem buscar a inserção de seus empreendimentos em redes organizadas de produção, que por sua vez dependem de boas condições de 
infraestrutura, produtos e serviços. Ao dirigir uma empresa, o agricultor passa agora a negociar com fornecedores de insumos, parceiros, distribuidores e/ou consumidores finais. A habilidade de negociação, quer seja interna (com associados e subordinados) ou externa (com fornecedores, clientes, concorrentes), necessita de desenvolvimento (LONGENECKER et al., 2013).

Os agricultores familiares apresentam dificuldade de inserção no ambiente agroindustrial, visto que a maior parte das agroindústrias beneficiadas não possui as características sociais da produção familiar, o que tem se mostrado nocivo à própria configuração do modelo de negócio, nesse caso deixando à margem os produtores mal-preparados ou sem condições de participar desse arranjo, o que confirma os estudos de Wesz Junior (2012). Os empreendedores precisam não somente se estabelecer em redes ou alianças estratégicas, mas também aprimorar as habilidades interpessoais, que são de extrema importância para facilitar captação de recursos, redução de custos e obtenção de maior competitividade, já que o processo de cooperação entre instituições é composto por pessoas (PAIVA JUNIOR; FERNANDES, 2012).

\subsubsection{Competência conceitual}

Os líderes da agroindústria de polpa de fruta de Bonito apresentam dificuldades em tomar decisões sob pressão e possuem baixa capacidade criativa para resolução de problemas. Nas agroindústrias de rapadura e castanha-de-caju, os líderes manifestaram boa capacidade na tomada de decisões. $\mathrm{Na}$ fábrica de Afogados da Ingazeira, a execução à risca do que foi planejado auxilia os gestores a tomar decisões rapidamente. Em Triunfo, os agricultores entrevistados apresentam pouca dependência de terceiros na resolução de conflitos. Considerando que um gestor com espírito empreendedor precisa ser hábil na solução de adversidades (PAIVA JUNIOR, 2008), merece destaque a relevância da competência conceitual para o agricultor, devido, em muitos casos, à grande dependência de terceiros para a resolução de problemas e à falta de uma visão integrada de negócios.

\subsubsection{Competência administrativa}

Os líderes da agroindústria de Bonito possuem pouca experiência administrativa e muita dificuldade em utilizar as funções básicas da administração; como o planejamento não é compartilhado por todos os associados da fábrica, seu alcance se dificulta. A organização dos recursos humanos da empresa é deficiente e inibe a potencialidade física e intelectual do pessoal e a aplicação do dinheiro disponível, o que faz que os equipamentos sejam subutilizados e a marca dos produtos finais, empobrecida. O orçamento, os custos de produção, as vendas e o desempenho individual dos colaboradores não são controlados ou analisados.

Na fábrica de Triunfo, os objetivos da agroindústria são bem definidos e conhecidos pelos colaboradores. A alocação de recursos é relativamente organizada, com destaque para a utilização do dinheiro e dos equipamentos, e os recursos são razoavelmente orientados e coordenados devido à relativa experiência administrativa das lideranças. Mesmo com o reconhecimento da importância dos clientes por parte dos agricultores, a opinião e a satisfação dos clientes ainda precisam ser priorizados.

Os líderes em Afogados da Ingazeira atribuem previamente tarefas aos trabalhadores, possuem experiência administrativa e utilizam indicadores de desempenho. Na organização da fábrica, destaca-se boa alocação dos recursos humanos e financeiros. A administração do tempo que cada trabalhador dedica à agroindústria não é levada em conta. Em geral, os recursos disponíveis têm sido bem direcionados e coordenados. Na função controle, acompanham as atividades e desempenho dos colaboradores, que se reúnem mensalmente para corrigir falhas na execução das atividades 
cotidianas. A falta de hábito em consultar a satisfação e a opinião dos clientes é deficiente nessa fábrica de castanha-de-caju.

Pires (2011) demonstra que, mesmo diante de condições adversas, como escassez de recursos, aridez, grande distância dos centros consumidores e custos elevados, produtores familiares do sul da França obtiveram êxito em seus empreendimentos por aliarem cooperativismo a um grau considerável de administração por parte dos associados. Zampier e Takahashi (2011) defendem que experiências empreendedoras, como criação de empresas e administração de negócios, potencializam o processo de aquisição de competências empreendedoras.

O desempenho de uma organização nem sempre se relaciona com as competências individuais dos trabalhadores; na verdade, são diversos os motivos do ambiente interno empresarial que restringem ou potencializam a expressão das competências (BRANDÃO; BORGES-ANDRADE; GUIMARÃES, 2012).

\subsubsection{Competência estratégica}

As lideranças da agroindústria de Bonito possuem deficiências na capacidade de inovar e na visão de médio e longo prazo. Em Triunfo, os líderes também apresentam dificuldade em inovar, porém vislumbram melhores cenários, como conquistar o mercado externo com seus produtos. Os agricultores entrevistados em Afogados da Ingazeira apresentam como potencialidade a boa capacidade de criação, que possibilitou mudanças positivas no processo de produção da castanha-decaju e que permitirá o aproveitamento dos resíduos de fabricação. Como deficiência, destaca-se a baixa visão para tomada de decisão estratégica na manutenção da competitividade da fábrica; é preciso considerar que, diante de um mercado competitivo, só resistem as empresas que inovam (FLEURY; FLEURY, 2004). Os agricultores pesquisados apresentam relativa resistência à inovação; o temor de muitos é, ao longo do tempo, perder a identidade de homem do campo. Conforme Wesz Junior e Trentin (2005), os produtos agroindustrializados de pequenos produtores carregam, em sua concepção, a cultura do local onde foram produzidos.

\subsubsection{Competência de comprometimento}

Os líderes da fábrica de polpa de fruta em Bonito apresentam baixo comprometimento, pois o tempo dedicado à agroindústria tem diminuído em comparação ao de outras atividades dos agricultores. Diante do atual cenário adverso para a fábrica, os produtores possuem dificuldade em enfrentar a situação de crise e tratam a agroindústria como atividade econômica secundária - aqui, há discordância com aquilo que afirma Paiva Junior (2008), que considera que essa competência é estimulada por valores pessoais. Não é apenas isso: em uma situação difícil e em que a fome está em jogo, como a enfrentada pela agroindústria, os agricultores se sentem fragilizados, o que acaba comprometendo a entrega e dedicação ao trabalho.

Na fábrica de rapadura em Triunfo, os trabalhadores dedicam cerca de oito horas diárias durante cinco dias por semana, o que lhes faz recear pela perda da identidade de agricultor familiar; ainda assim, apresentam boa capacidade em resolver situações difíceis. Os líderes entrevistados na fábrica de castanha-de-caju, em Afogados da Ingazeira, possuem bom comprometimento na agroindústria e boa capacidade para contornar adversidades.

\subsubsection{Competência de equilíbrio entre trabalho e vida pessoal}

Constata-se que duas das três lideranças entrevistadas em Bonito possuem fraco controle do embate entre vida pessoal e profissional, pois suas atividades na fábrica são frequentemente interrompidas ou fragilizadas diante de problemas 
pessoais. O desgaste emocional e a maior chance de fracasso citados por Longenecker et al. (2013) são os dois maiores fatores que inibem o empreendedorismo, entre os agricultores pesquisados. Em Triunfo, os líderes separam ao máximo a vida pessoal da profissional, o que se deve a terem maior controle da organização formal da empresa. Semelhante à situação encontrada em Bonito, as lideranças da fábrica de castanha-de-caju em Afogados da Ingazeira apresentam deficiência no equilíbrio entre vida pessoal e profissional.

As cooperativas devem promover a separação entre propriedade e gestão, o que diminui a possibilidade de obtenção de benefícios por parte dos gestores, além de descentralizar a tomada de decisão (COSTA; AZEVEDO; CHADDAD, 2012).

\subsection{Ações e condições de trabalho dos técnicos de apoio para a formação de agricultores empreendedores}

\subsubsection{Processo de transição do agricultor familiar tradicional para agricultor empreendedor}

O técnico da Adagro afirmou que "as agroindústrias são importantes para fornecer mais alimentos à população e propiciar maior renda ao agricultor. Porém, devem atender as exigências sanitárias, o que não tem ocorrido" (informação verbal). A adequação dos produtores a essas exigências só seria possível depois de conscientização e mobilização por parte das organizações de produtores rurais (SULZBACHER, 2009), mas como eles poderiam chegar a esse nível? Para isso, o papel dos técnicos é fundamental: eles devem estar muito bem capacitados gerencialmente e precisam ter claro o que se entende por visão empreendedora. O técnico da Adagro, por exemplo, revelou estar capacitado apenas para o aspecto da inspeção sanitária. Observa-se carência de visão mais ampla dos técnicos de apoio.
Já para o técnico do BNB, isso é perfeitamente possível, mas "os agricultores necessitam de um bom planejamento, maior e melhor assessoramento de qualidade, principalmente no início dos empreendimentos (elaboração e execução de projetos)" (informação verbal). O técnico do Centro Sabiá afirmou que,

geralmente, os agricultores familiares ingressam no empreendedorismo após contato com novas formas de produzir, quando participam de feiras, intercâmbio entre produtores, depois de receber visitas e questionamentos dos clientes sobre a forma de produção e atributos dos produtos. As agroindústrias instaladas próximas às empresas de suporte apresentam maior possibilidade de êxito (informação verbal).

Dado o pequeno tamanho da amostra, não foi possível confirmar essa afirmação.

O técnico do IPA de Recife acredita na transição, mas não concorda com a visão de que o agricultor se tornará um empresário. Já para o técnico do IPA de Serra Talhada, "os produtores avançaram bastante no conhecimento técnico da fabricação dos produtos. Porém, ainda aproveitam pouco os subprodutos das pequenas agroindústrias" (informação verbal).

Já segundo o técnico do IPA de Afogados da Ingazeira,

nos lugares que têm dado certo, o processo de transição ao empreendedorismo tem possibilitado uma melhor qualidade de vida para o produtor rural. Porém, sedeve ter o cuidado para que o agricultor, ao administrar uma agroindústria, não deixe de cultivar a terra. Para isso, é importante a participação de todos os membros da família nesses negócios mediante uma maior eficiência na divisão de trabalho (informação verbal).

Para o técnico do Incra, os pequenos agricultores ainda necessitam se adequar às demandas 
do mercado para evitar tanta exploração dos intermediários e de outros envolvidos na comercialização.

O técnico da SARA defende que a transição ao empreendedorismo é de extrema importância para o fortalecimento da agricultura familiar. Para tal, em Pernambuco foi criada a Secretaria Executiva de Agricultura Familiar.

O técnico entrevistado do ProRural afirma que "o empreendedorismo é um dos requisitos para atingir a tão buscada melhoria da qualidade de vida do homem do campo. No entanto, se faz necessária uma assessoria permanente ou muito próxima dos agricultores, principalmente nos quesitos gestão e comercialização" (informação verbal).

\subsubsection{Desafios de lidar com o pequeno agricultor empreendedor}

O técnico da Adagro disse haver resistência natural dos produtores à mudança de atitude, principalmente quanto a se adequar às exigências sanitárias.

Para o técnico do BNB,

os dilemas são a falta de conhecimento sobre a correta administração dos recursos próprios (terra, insumos, matéria-prima, propriedade e fábricas), que dificulta a boa capacidade de tornar as atividades agropecuárias lucrativas e, por consequência, honrar o crédito financiado, esse que em muitos casos é mal aplicado e talvez nem fosse preciso para a criação de empreendimentos, pois foi fruto de um deficiente planejamento da produção (informação verbal).

Segundo o entrevistado do Centro Sabiá,

os maiores desafios são a adequação às exigências sanitárias, a obtenção dos selos de qualidade, o registro de produtos processados e a falta de cuidados de higiene na manipulação e beneficiamento da matéria-prima. Os agricultores que ingressam no empreendedorismo possuem maior articulação, "mente aberta" para sugestões dos clientes (informação verbal).

Porém, em uma das três agroindústrias pesquisadas, os gestores estão bastante isolados no relacionamento com concorrentes e empresas de apoio. Sua visão é semelhante à do técnico da agência de inspeção, que destaca a dificuldade em manipular os produtos beneficiados com cuidados de higiene.

Conforme o entrevistado da Coopagel,

a dificuldade recai em trabalhar com o agricultor sobre a importância da embalagem, do marketing, da divulgação e de novas vendas para os seus produtos. Também existe a dificuldade de adequação do agricultor às exigências sanitárias, pois sua identidade é forte e ele teme perdê-la no processo de modernização (informação verbal).

Para o técnico do IPA de Recife, é desafiante a resistência do produtor rural aos processos de modernização. Igualmente, o imediatismo do agricultor dificulta o planejamento de suas atividades. Já o técnico do IPA de Afogados da Ingazeira disse se sentir isolado para atender com eficácia os agricultores e acredita que há carência de compreensão na comunicação, devido à baixa escolaridade do agricultor, agravada ainda pelo fato de a infraestrutura local ser deficiente para capacitação dos agricultores - exemplos são a falta ou o despreparo das escolas técnicas, de órgãos de apoio, de prefeituras e de universidades.

Para nossos agricultores familiares se tornarem empreendedores rurais, é necessária uma mudança de visão, como defende o entrevistado do IPA de Recife ao relatar que "os produtores rurais provenientes de algumas regiões do Estado de Pernambuco, como os da Zona da Mata (região canavieira) possuem um perfil de trabalhadores assalariados, o que é diferente da visão empreendedora" (informação verbal). Essa opinião é 
compartilhada por Leite (2000) ao afirmar que há dificuldade do novo empreendedor em mudar sua postura de empregado para empresário.

O entrevistado do IPA de Afogados da Ingazeira cita a relevância dos centros de formação técnico-educacional para o sucesso da transição do agricultor familiar tradicional para um empreendedor rural, bem como a contínua formação escolar do produtor, pois o empreendedorismo é possível de aprender, desde que se condicionem as pessoas para isso (DORNELAS, 2008). O entrevistado também destaca a inclusão da família nos pequenos empreendimentos do campo, pois isso facilita a reorganização das atividades produtivas e inclui no trabalho mulheres, jovens e idosos (MIOR, 2008).

Diferente do que relata o técnico da Adagro, o entrevistado do MAPA atribui a dificuldade das pequenas agroindústrias em se adequar à legislação sanitária e à obtenção do selo do registro ao despreparo dos técnicos de empresas de consultoria em gestão de negócios no campo. Diante de todas as reclamações dos agricultores no tratamento padrão para as agroindústrias de diversos portes, o técnico do MAPA rebate ao alegar que

os fiscais são flexíveis no atendimento aos negócios de pequeno porte, e concordamos com a necessidade de atualização das normas em relação ao tamanho dos empreendimentos. Por exemplo, a fiscalização para uma pequena fábrica de rapadura e açúcar mascavo segue os mesmos preceitos da inspeção de uma grande usina produtora de açúcar. A legislação é indiferente ao porte e especificidades das agroindústrias, e somente as diferenciam pelos tipos de produtos: vinhos e vinagres, polpas e sucos de frutas tropicais, dentre outros (informação verbal).

O entrevistado do Incra sente necessidade de maiores articulações interinstitucionais com parceiros em potencial; também alega que o governo deve priorizar o processo de reorganização do espaço rural (reforma agrária), para que o Incra possa contribuir com maior eficiência no planejamento da vida no campo.

Para o entrevistado da SARA, a baixa escolaridade de muitos produtores e também a falta de prática em gestão de negócios dificultam o trabalho dos técnicos. A estratégia da SARA se apresenta relevante ao usar metodologias de capacitação dos agricultores com foco na gestão dos recursos produtivos e no emprego das funções básicas da administração. Essas metodologias merecem destaque por atender a real necessidade dos produtores rurais e empreendedores, conforme relata o técnico do BNB ao alegar que a administração de novos negócios no meio rural nem sempre é eficiente. Apesar de reconhecer a carência do agricultor sobre a gestão empreendedora, o técnico da SARA revela que seu pessoal de campo necessita de maior preparo acerca desse tema.

O técnico do ProRural observa que os agricultores estão sendo mal acompanhados pelas empresas de consultoria e acredita que isso aconteça devido à deficiente formação acadêmica dos técnicos extensionistas. Já o entrevistado da UFRPE discorda desse argumento, embora o reforce, pois, segundo ele

a Universidade não tem como fornecer todo o suporte para a formação dos profissionais no campo da administração rural, visto que os cursos (disciplinas) são em geral de pouca duração (cerca de 80 horas em seis meses). O que os professores ministram são teorias, e o futuro técnico deverá construir seus próprios conceitos elou buscar exercitar a base fornecida em sala de aula, devido à complexidade do assunto, que só pode ser aprendido após certa vivência profissional (informação verbal).

\subsubsection{Algumas dificuldades decorrentes da Agroindústria de Pedra do Rodeadouro, Bonito}


A dificuldade dos agricultores em comercializar produtos in natura foi trocada por outra: vender produtos industrializados, que agora exige maior conhecimento deles em embalagens e padronização de produtos, mercados, técnicas apropriadas de marketing e comercialização. Devido à ausência do selo de inspeção sanitária, nem mesmo os distribuidores intermediários têm adquirido os produtos dessa fábrica.

Para que o agricultor familiar se insira no processo de agroindustrialização, deve compreender todo o funcionamento do sistema de distribuição de alimentos, padronização e qualidade dos produtos industrializados (WILKINSON, 2008).

Devido à falta de espaço para estocagem das frutas in natura, processadas em pasta base e/ou polpa de fruta, a vida útil da matéria-prima colhida não tem sido aumentada; por isso, a venda de frutas a preços baixos durante a safra e o desperdício acontecem demasiadamente. Por falta de selo de inspeção sanitária, embalagens adequadas, baixa capacidade de estocagem e poucas vendas, a agregação de valor da polpa de fruta em relação às frutas in natura não tem acontecido. Essa realidade aponta para um reparo ao que disse Batalha (1995), já que nem sempre a presença de uma agroindústria possibilita redução de desperdício de matéria-prima ou agrega valor à produção.

Diferente do que ocorre nas agroindústrias de rapadura e castanha-de-caju e do que se projetou para a fábrica de polpa de fruta em 2003, a agroindústria de doces e polpa de fruta do Povoado de Pedra do Rodeadouro em Bonito não tem auxiliado no desenvolvimento da comunidade. Nesse caso, há consonância com o que dizem Goodman, Sorj e Wilkinson (1985) sobre a relação entre agroindústria e melhoria das condições sociais no campo. O associativismo local está fragilizado pela atual situação da fábrica e por falta de confiança dos associados nas lideranças da agroindústria. A sustentação de uma agroindústria depende muito do seu grau de organização associativa. Além disso, se evidenciou concordância com Mior (2008), ao argumentar que essa transição ao empreendedorismo é um estágio de difícil conquista.

Mendonça e Alves (2012) mostram, por meio de estudo na região sisaleira da Bahia, que a profissionalização dos agricultores levou a um estado de desenvolvimento rural da população.

\section{CONCLUSÃO}

Algumas considerações sobre as competências empreendedoras pesquisadas: a baixa infraestrutura é uma das causas do isolamento dos produtores e dificulta a busca por novos contratos de venda e inserção em mercados. Numa agroindústria em que os agricultores possuem tarefas preestabelecidas, ocorre boa sintonia entre seus membros e há mais facilidade em alcançar o planejamento e também considerável diminuição do desgaste emocional. Por outro lado, quando os recursos são mal direcionados, o desempenho dos agricultores diminui e a coordenação se dificulta, o que resulta num baixo retorno financeiro dos investimentos da agroindústria, que não potencializa sua capacidade de produção. Objetivos bem definidos facilitam o cumprimento do que foi planejado. A utilização de indicadores de desempenho e uma maior experiência dos líderes permitem a melhoria contínua da produtividade do trabalho executado.

A capacidade dos líderes em inovar e enxergar o futuro melhora a sustentação da empresa e facilita a inserção da agroindústria em novos mercados. O equilíbrio entre trabalho e vida pessoal tem refletido diretamente no comprometimento e no desempenho dos agricultores pesquisados. O elevado grau de informalidade do trabalho na agroindústria é um dos fatores responsáveis pela deficiência por parte de alguns agricultores. A desorganização financeira encontrada na agroindústria de Bonito dificulta a melhoria das condições da fábrica e resulta em menor retorno das atividades desempenhadas; a deficiência em marketing e comercialização e na 
importância que se dá à conquista e manutenção de clientes impossibilita que uma agroindústria elimine a figura do atravessador.

Apenas na fábrica de polpa de fruta, em Bonito é que a agroindustrialização não tem se consolidado como atividade socioeconômica para a comunidade beneficiada. Os resultados negativos recaem no despreparo dos agricultores líderes. As agroindústrias Mãos Crioulas, de castanha-decaju, em Afogados da Ingazeira, e Adessu, de rapadura, em Triunfo, apresentaram maior êxito durante a pesquisa; os agricultores têm sido bem assessorados desde a implantação e as fábricas estão instaladas com boa infraestrutura.

Os órgãos de apoio devem se adequar com investimentos em recursos financeiros, humanos e físicos para a tendência de profissionalização do agricultor familiar. As ações adotadas estão aquém do suficiente para atender as particularidades dos pequenos produtores rurais. São considerados insuficientes o preparo do pessoal técnico (formação, experiências anteriores etc.), a infraestrutura de apoio (veículos, diárias etc.) e as metodologias em projetos de implantação e estudos técnicos (planos de negócios, estudos de comercialização etc.). Necessitam de melhorias as metodologias em cursos, seminários, treinamentos, grupos de discussão, reuniões e oficinas, bem como são necessários avanços como maior oferta e atualização de valores nas condições das linhas de crédito disponíveis.
Deve haver maior rigor na elaboração dos projetos de implantação das agroindústrias e na análise, por parte dos órgãos de financiamento. A pressa em aprovar os pleitos tem se sobreposto à qualidade, e os resultados negativos recaído nos produtores familiares.

As agroindústrias rurais devem produzir com qualidade e segurança alimentar, se utilizando de higiene, boas práticas de fabricação etc.; seria importante, então, que a fiscalização pública orientasse os produtores. Para isso, torna-se também importante o trabalho de construir confiança mútua e que haja maior cordialidade por parte dos fiscais. Também se faz necessária menor morosidade por parte dos órgãos competentes. Sugerem-se parcerias com universidades e escolas técnicas (empresas juniores) para auxiliar em algumas etapas do registro e fiscalização desses empreendimentos. Para registro dos produtos e legalização estadual e federal das fábricas, são importantes a desburocratização do processo, a redução de tarifas e o respeito à cultura local e às particularidades dos empreendimentos.

Tendo em vista o sucesso alcançado por outras iniciativas, há possibilidade da transição dos agricultores, pois o processo de inclusão do pequeno agricultor ao empreendedorismo tem obtido êxito nas iniciativas que proporcionaram condições suficientes para o estímulo à assimilação das competências empreendedoras por parte dos agricultores.

\section{REFERÊNCIAS}

ABRAMOVAY, R. Desenvolver os territórios fortalecendo o empreendedorismo de pequeno porte. In: FÓRUM INTERNACIONAL TERRITÓRIO, DESENVOLVIMENTO RURAL E DEMOCRACIA, 1., 2003, Fortaleza. Anais... Brasília: IICA, 2003.

BARDIN, L. Análise de conteúdo. Tradução de Luís Antero Reto e Augusto Pinheiro. 4. ed. Lisboa: Edições 70, 2008.
BATALHA, M. O. (Org.). Gestão Agroindustrial, vol. 1. 3. ed. São Paulo: Atlas, 2007.

- Gestão do sistema agroindustrial: a formação de recursos humanos para o agribusiness brasileiro. Gestão e Produção, São Carlos, v. 2, n. 3, dez. 1995.

BRANDÃO, H. P.; BORGES-ANDRADE, J. E.; GUIMARÃES, T. A. Desempenho organizacional e suas relações com 


\section{REFERÊNCIAS}

competências gerenciais, suporte organizacional e treinamento. Revista de Administração, São Paulo, v. 47, n. 4, p. 523-539, out./dez. 2012.

BRASIL. Lei n. 11.326, de 24 de julho de 2006. Diário Oficial da União, Brasília, DF, 25 jul. 2006.

BUAINAIN, A. M. (Coord.). Agricultura familiar e inovação tecnológica no Brasil. características, desafios e obstáculos. Campinas: Edunicamp, 2007.

CAMPANHOLA, C.; SILVA, J. F. G. O novo rural brasileiro: rendas das famílias rurais, v. 5. Brasília: Embrapa Informação Tecnológica, 2004. 495 p.

COSTA, D. R. M.; AZEVEDO, P. F.; CHADDAD, F. R. Determinantes da separação entre propriedade e gestão nas cooperativas agropecuárias brasileiras. Revista de Administração, São Paulo, v. 47, n. 4, p. 581-595, out./dez. 2012.

DORNELAS, J. C. A. Empreendedorismo: transformando ideias em negócios. 3. ed. Rio de Janeiro: Elsevier, 2008. 232 p.

DRUCKER, P. F. Inovação e espírito empreendedor (entrepreneurship): prática e princípios. Tradução de Carlos J. Malferrari. 1. ed. São Paulo: Pioneira, 2005. 378 p.

FLEURY, A. C.; FLEURY, M. T. L. Estratégias empresariais e formação de competências: um quebra-cabeça caleidoscópico da indústria brasileira. 3. ed. São Paulo: Atlas, 2004.

FRANCO, M. L. P. B. Análise de conteúdo. 3. ed. Brasília: Liber, 2008.

GIBBS, G. Análise de dados qualitativos. Tradução de Roberto Cataldo Costa. Porto Alegre: Artmed; Bookman, 2009. 198 p.
GOODMAN, D.; SORJ, B.; WILKINSON, J. Agroindústria, políticas públicas e estruturas sociais rurais. Revista de Economia Politica, v. 5, n. 4, p. 31-56, 1985.

LAU, T. L. M. et al. The entrepreneurial behaviour inventory: a simulated incident method to assess corporate entrepreneurship. International Journal of Entrepreneurial Behaviour \& Research, v. 18, n. 6, 2012.

LEITE, E. F. O fenômeno do empreendedorismo: criando riquezas. 2. ed. Recife: Bagaço, 2000. 554 p.

LONGENECKER, J. G. et al. Administração de pequenas empresas. Tradução de Oxbridge Centro de Idiomas. 13. ed. 3. reimp. São Paulo: Cengage Learning, 2013.

LOPES, L. A. B.; NANTES, J. F. D. Capacitação e Empreendedorismo no Setor Rural. In: ZUIN, L. F. S.; QUEIROZ, T. R. Agronegócio: gestão e inovação. 3. ed. São Paulo: Saraiva. p. 364-393, 2008.

MAN, T. W. Y. Developing a behaviour-centred model of entrepreneurial learning. Journal of Small Business and Enterprise Development, v. 19, n. 3, p. 549-566, 2012.

MAN, T. W. Y.; LAU, T. L. M. The context of entrepreneurship in Hong Kong: an investigation through the patterns of entrepreneurial competencies in contrasting industrial environments. Journal of Small Business and Enterprise Development, v. 12, n. 4, 2005.

MCCLELLAND, D. C. Testing for competence rather than for intelligence. American Psychologist, Washington, n. 28, p. 1-4, jan. 1973.

MENDONÇA, P. M. E.; ALVES, M. A. Institutional entrepreneurship and professionalization of the rural development of the sisal region in Brazil. Revista de 


\section{REFERÊNCIAS}

Administração, São Paulo, v. 47, n. 3, p. 489-499, jul./ set. 2012.

MIOR, L. C. Trajetórias das agroindústrias familiares rurais no estado de Santa Catarina (Brasil). In: CONGRESO INTERNACIONAL DE LA RED SIAL, 4., Mar del Plata. Anais... Mar del Plata: IICA, 2008.

MÜLLER, G. Agricultura e industrialização do campo no Brasil. Revista de Economia Política, v. 2, n. 6, p. 47-77, 1982.

NEVES, M. F.; CONEJERO, M. A. Sistema agroindustrial da cana: cenários e agenda estratégica. Economia Aplicada, Ribeirão Preto, v. 11, n. 4, p. 587-604, 2007.

OLIVEIRA, M. M. Associativismo e cooperativismo no desenvolvimento local. In: SANTOS, M. S. T.; CALLOU, A. B. F. (Orgs.). Associativismo e desenvolvimento local. Recife: Bagaço, 2006. p. 153-184.

PAIVA JUNIOR, F. G. Empreendedorismo e competência do gestor de agronegócio. In: CALLADO, A. A. C. (Org.). Agronegócio. 2. ed. São Paulo: Atlas, 2008, p. 48-57.

PAIVA JUNIOR, F. G.; FERNANDES, N. C. M. A contribuição da competência relacional do empreendedor para aperfeiçoar a qualidade de relacionamento entre empresas de base tecnológica. Revista de Administração e Inovação, São Paulo, v. 9, n. 3, p. 53-76, jul./set. 2012.

PAIVA JUNIOR, F. G. et al. A contribuição das competências empreendedoras para a formação de dirigentes em sistemas de incubação. In: ENCONTRO NACIONAL DE ENGENHARIA DE PRODUÇÃO, 26., 2006, Fortaleza. Anais... Fortaleza: Abepro, 2006.

PIRES, M. L. L. S. Cooperativismo e dinâmicas produtivas em zonas desfavorecidas: o caso das pequenas cooperativas agrícolas do Sul da França. Sociologias, Porto Alegre, ano 13, n. 26, p. 228-261, jan./abr. 2011.
RUPPENTHAL, J. E.; CIMADON, J. E. O processo empreendedor em empresas criadas por necessidade. Gestão e Produção, São Carlos, v. 19, n. 1, p. 137-149, 2012.

STRAUSS, A.; CORBIN, J. Pesquisa qualitativa: técnicas e procedimentos para o desenvolvimento da teoria fundamentada. 2. ed. 1. reimp. Porto Alegre: Artmed, 2009.

SULZBACHER, A. W. Agroindústria familiar rural: caminhos para estimar impactos sociais. In: ENCONTRO NACIONAL DE GEOGRAFIA AGRÁRIA, 19., 2009, São Paulo. Anais... São Paulo: USP, 2009. p. 1-23.

WESZ JUNIOR, V. J. Política pública de agroindustrialização na agricultura familiar: uma análise do Pronaf-agroindústria. RESR, Piracicaba, v. 48, n. 4, p. 567-596, out./dez. 2010.

WESZ JUNIOR, V. J.; TRENTIN, I. C. L. Desenvolvimento territorial com agroindústrias familiares. In: CONGRESSO BRASILEIRO DE ECONOMIA E SOCIOLOGIA RURAL. RIBEIRÃO PRETO, 43., 2005. Anais... Ribeirão Preto: Sober, 2005.

WILKINSON, J. Transformações e perspectivas dos agronegócios brasileiros. Revista Brasileira de Zootecnia, Viçosa, v. 39, p. 26-34, jul. 2010.

Mercados, redes e valores: o novo mundo da agricultura familiar. Porto Alegre: UFRGS, 2008.

ZAMPIER, M. A.; TAKAHASHI, A. R. W. Competências empreendedoras e processos de aprendizagem empreendedora: modelo conceitual de pesquisa. Cadernos Ebape.BR, Rio de Janeiro, v. 9, ed. esp., p. 564-585, jul. 2011.

ZARIFIAN, P. Objetivo competência: por uma nova lógica. Tradução de Maria Helena C. V. Trylinski. São Paulo: Atlas, 2001. 197 p. 